\title{
Simulation comes of age
}

\author{
Geoff Norman
}

Published online: 11 April 2014

(c) Springer Science+Business Media Dordrecht 2014

Medical simulation has actually been around a very long time. I still remember my first encounter with a "high fidelity" simulation back when I was a newbie in medical education. It was developed by Bill Harless (Harless et al. 1971), with a very large NIH grant. It ran on a mainframe somewhere (there were only mainframes in those days). The simulation began with a colour video of the patient walking down a beach in southern California, and ended with her dying of a heart attack. Well, not exactly. That was one possible ending, which was decided by the digital grim reaper, a random number generator somewhere in the bowels of the computer. In between, the candidate could ask the computer any question she wanted by typing it in, in ordinary language, and the patient would respond appropriately (well, most of the time).

From today's vantage, this seems pretty well routine. But in 1971, many of us didn't yet own a colour TV, let alone a video recorder that was computer controlled. Computers occupied large buildings, and you interacted with them by handing in your boxes of cards at the window and picking up your newsprint output a day later at the outbox. To put it in perspective, the computer on board Apollo 13 at about the same time had $2 \mathrm{~KB}$ of RAM, and ran at a CPU time of 1 microsecond. My laptop has $1,000,000 \mathrm{~KB}$, and runs at a CPU time of less than a nanosecond.

Unfortunately, CASE was too clever for its own good. I once heard that it cost $\$ 50,000$ to produce a single case. Harless et al. (1971) reported that the author, even after training, had to invest over $6 \mathrm{~h}$ just to input the necessary data. Moreover, the technological demands made it inaccessible for educational purposes. No institution could afford a single CASE setup, let alone a computer learning lab (even if one existed, which it did not).

As we all know, technological innovations have occurred at lightning pace, so that such a system would now be viewed as a straightforward "virtual patient" application, not even beginning to stretch the capacity of the average laptop. But our pedagogical understanding of the value of simulation has not proceeded apace. We continue our love affair with realistic, "high fidelity" simulation, and readily accept that the more authentic (and more

G. Norman $(\bowtie)$

McMaster University, Hamilton, ON, Canada

e-mail: norman@mcmaster.ca 
expensive) the simulation, the better the learning. As a result, nearly every medical school has now acquired a "Harvey" heart sound simulator, at a cost of $\$ 50,000$ or so. (Not only has Harvey shed about half the original cost, according to the website http://www.gcrme. med.miami.edu/harvey_features.php, he's gone on a crash diet and now weighs $500 \mathrm{lb}$. less than he used to. Which begs the issue of how much he once weighed. No wonder he has heart problems!). And what makes him so good? Again, the website:

This full size manikin realistically simulates nearly any cardiac disease at the touch of a button.... No other simulator presents cardiac bedside findings to the level of detail and fidelity fund in Harvey.

Harvey simulates 30 conditions. Unfortunately, Harvey has only one example of 30 conditions. Learning heart sounds from Harvey would be like learning to recognize classical composers by listening to a 1 min passage from each of Bach, Beethoven and Wagner.

Harvey is not alone. In fact, it's a crowded field. The $\$ 80,000$ METI simulator is headlined, in 48 point font, as "Unmatched realism with objective performance." $\mathrm{He} / \mathrm{she}$ (I mean it. The important bits are interchangeable) has all the whistles and bells.

http://www.ahcsimcenter.umn.edu/prod/groups/ahc/@pub/@ahc/@ simcenter/documents/ asset/ahc_asset_030078.pdf:

Reactive eyes, blink, neuro assessment

Realistic airway, breakaway teeth, voice

Trachea with realistic landmarks

Carotid pulse

Pneumothorax decompression

Independent chest excursion

Breath sounds

Heart sounds

Intercostal palpable ribs

Chest compression

ECG

Defibrillation

Pacing

IV arm

Bilateral brachial pulse

Interchangeable genitalia

Urinary output

Thumb twitch

One wonders what medical condition requires both a carotid pulse and a thumb twitch for diagnosis.

It is clear from their history that medical simulators bear allegiance to the aviation simulator. METI is explicit. Again, from their website:

Only in the aviation industry can you find a valid comparison to the healthcare field's life-and-death necessity for rapid response, combined with unerring knowledge skill and teamwork. For both pilots and healers it's an inescapable dilemma: where mistakes happen lives can be lost. So it was no coincidence when computer simulation as a primary learning tool made the evolutionary leap from ultra-engineered flying machines to the natural intricacies of the human body. 
Given the cost of many simulators, it is hardly surprising that few medical schools can afford more than one of each. But this has consequences-with only one simulator, it is very difficult to build simulation into the curriculum in a meaningful way, since one cannot permit open access to the simulator. The resource is too scarce.

There is a certain irony in this. While simulation has many valuable features, which have been articulated by numerous authors, certainly a major advantage is that, in a healthcare world of shrinking access to appropriate patients brought about by changes in the system itself such as reduced use of inpatient facilities, working hour restrictions, increased and more diverse learners, simulation could have an essential role in expanding the learning opportunities. But if the cost of simulation is so high that access of individual learners must come on a priority basis, then it is incapable of fulfilling this role.

Which is a pity. Educators are recognizing the importance of deliberate practice, and lots of it, in the development of competence. Moreover, we are learning that practice can be made much more effective through strategies like distributed practice and mixed or interleaved practice (Cook et al. 2013; Rohrer 2012). But these truly dramatic gains can only be achieved if we can gain control of the sequence of events, so that each student has the opportunity to practice optimally, which cannot be achieved if we have one simulator for several hundred students and each simulator has only one example of each condition.

One way the conundrum can be relieved is by abandoning our requirement for "authenticity at any cost". We now have evidence (Norman et al. 2012) that increased authenticity does not necessarily lead to better learning of many skills. Also, a series of studies by Durning et al. (2012), contrasting patient cases represented as paper cases, videos and standardized patients has shown that "Increasingly authentic instructional formats did not significantly improve clinical reasoning performance." In arriving at this conclusion, we are regrettably rediscovering a conclusion reached in the aviation literature at least 15 years ago:

In sum, more is not necessarily better. Generally, the level of simulation fidelity does not translate to learning. High fidelity simulations ... should be used as determined by training and task requirements, cost and learning objectives (Salas et al. 1998).

However, by abandoning the use of authenticity as a criterion, we have removed one basis for choice of simulation, but not replaced it with anything else.

In this issue, there are two review papers that attempt to more carefully examine the critical underlying dimensions of a simulation. Haji et al. (2013) draw a strong distinction between simulation-based medical education and simulation-augmented medical education, where the latter explicitly links the simulator-based experience to other educational experiences occurring concurrently. This then highlights the integration of the simulation experience in the curriculum treating it as one important element, rather than an "add-on" experience.

Grierson (2014) attempts a comprehensive reinterpretation of the notion of fidelity, anchoring it to "the fundamental information-processing events that underpin human performance." Fidelity is not simply a property of the simulator, but rather reflects the ability of the simulator to accurately mimic the critical cognitive and motor elements in the criterion task. A particular eye simulator may have high fidelity in assessing the psychomotor aspects of ophthalmoscopic examination, but low fidelity in reproducing the retinal features necessary to acquire the perceptual skills. In this sense, fidelity becomes like Messick's (1980) validity - a property of the interaction between the instrument and the criterion task. 
These two review articles are nicely complemented by two empirical studies in this issue. Groenier et al. (2013) examines the extent to which basic cognitive abilities relate to performance in laparoscopy, which puts some of Grierson's ideas on an empirical footing. Isaranuwatchai et al. (2013) examines cost-effectiveness of various simulators, an approach that critically examines the notion that more (money) is better in terms of learning. (As an interesting aside, showing how confused is our current notion of fidelity, they define a $\$ 16,000$ virtual reality IV simulator as "low fidelity" and a $\$ 600$ static simulator as "mid-fidelity"). Finally, Hatala et al. (2014) reports a secondary analysis of a large systematic review directed at examining the characteristics of effective feedback, emphasizing that it is how the simulator is implemented, not the simulator per se that determines learning. Again, the results challenge some of our cherished beliefs. About 1/3 of the studies show that feedback leads to poorer performance. And two studies showed that, when the criterion occurs some time later or involves a transfer task, "terminal feedback" occurring at the end of the session is more effective than intensive concurrent feedback.

Taken together, these papers point us in a new direction in our understanding of the appropriate role of simulation. They are a beginning of a new era in which the remarkable learning gains achievable through educationally appropriate application of simulation can be achieved at moderate cost.

\section{References}

Cook, D. A., Hamstra, S. J., Brydges, R., Zendejas, B., Szostek, J. H., Wang, A. T., et al. (2013). Comparative effectiveness of instructional design features in simulation-based education: Systematic review and meta-analysis. Medical Teacher, 35(1), e867-e898.

Durning, S. J., Dong, T., Artino, A. R., Jr, LaRochelle, J., Pangaro, L. N., van der Vleuten, C., et al. (2012). Instructional authenticity and clinical reasoning in undergraduate medical education: a 2-year, prospective, randomized trial. Military Medicine, 177(9 Suppl), 38-43.

Greirson, L. (2014). Information processing, specificity of practice, and the transfer of learning: Considerations for reconsidering fidelity. Advances in Health Sciences Education. doi:10.1007/s10459-0149504-X.

Groenier, M., Schraagen, J. M. C., Miedema, H. A. T., \& Broeders, I. A. J. M. (2013). The role of cognitive abilities in laparoscopic simulator training. Advances in Health Sciences Education. doi:10.1007/ s10459-013-9455-7.

Haji, F. A., Hoppe, D. J., Morin, M. P., Giannoulakis, K., Koh, J., Rojas, D., \& Cheung, J. J. H. (2013). What we call what we do affects how we do it: a new nomenclature for simulation research in medical education. Advances in Health Sciences Education, 1-8. doi:10.1007/s10459-013-9452-x.

Harless, W. G., Drennon, G. G., Marxer, J. J., Root, J. A., \& Miller, G. E. (1971). CASE: A computer-aided simulation of the clinical encounter. Academic Medicine, 46(5), 443-448.

Hatala, R., Cook, D. A., Zendejas, B., Hamstra S. J., \& Brydges, R. (2014). Feedback for simulation-based procedural skills training: A meta-analysis and critical narrative synthesis. Advances in Health Sciences Education. doi:10.1007/s10459-013-9462-8.

Isaranuwatchai, W., Brydges, R., Carnahan, H., Backstein, D., \& Dubrowski, A. (2013). Comparing the cost-effectiveness of simulation modalities: A case study of peripheral intravenous catheterization training. Advances in Health Sciences Education. doi:10.1007/s10459-013-9464-6.

Messick, S. (1980). Test validity and the ethics of assessment. American Psychologist, 35(11), 1012.

Norman, G., Dore, K., \& Grierson, L. (2012). The minimal relationship between simulation fidelity and transfer of learning. Medical Education, 46(7), 636-647.

Rohrer, D. (2012). Interleaving helps students distinguish among similar concepts. Educational Psychology Review, 24(3), 355-367.

Salas, E., Bowers, C., \& Rhodenizer, L. (1998). It's not how much you have but how you use it. The International Journal of Aviation Psychology, 8, 197-208. 